\title{
Survival Analysis of Extra-Alveolar Tads Used for Orthodontic Anchorage
}

\author{
Reshma Mohan ${ }^{1}$ and Ravindra Kumar Jain ${ }^{2}$ \\ ${ }^{1}$ Department of Orthodontics and Dentofacial Orthopaedics Saveetha Dental College and Hospital, \\ Saveetha Institute of Medical and Technical Sciences, Saveetha University 162, Poonamallee \\ High Road, Chennai-600077, Tamil Nadu,India \\ ${ }^{2}$ Associate Professor Department of Orthodontics and Dentofacial Orthopaedics Saveetha Dental \\ College and Hospital, Saveetha Institute of Medical and Technical Sciences, Saveetha University 162, \\ Poonamallee High Road, Chennai-600077, Tamil Nadu,India
}

\section{ABSTRACT}

The objective of this study was to determine the survival rate of extra-alveolar implants after three months of placement. Also, a questionnaire on the subject's response to the implants were distributed. The records of patients who had extraalveolar implants placed in the department of orthodontics were collected. A total of 32 samples were selected for this study - 7 Buccal Shelf (BS) implants and 25 Infra-Zygomatic Crest (IZC) implants. Stability of the TADs were checked using probe and tweezer on the third review. A questionnaire consisting of five questions were distributed to the subjects . Descriptive Statistics was calculated in terms of frequencies and percentages using SPSS software 23.00. Chi-square association test was also performed to associate the extra-alveolar TADs and the discomforts experienced after its placement. The results of this study showed that out of 32 implants only two reported with failure. From a patient point of view, restricted mouth opening, mild swelling was noted during the initial few days of placement. In this study , a high success rate of 93.75\% was recorded for extra-alveolar TADs. Patient discomfort was observed initially after the placement of the TADs which subsided over a period of 2 weeks.

KEY WORDS: BUCCAL SHELF IMPLANTS, INFRA-ZYGOMATIC IMPLANTS, SURVIVAL ANALYSIS.

\section{INTRODUCTION}

A fundamental aspect of orthodontic biomechanics is anchorage control. During therapy, poor anchorage control may increase treatment time leading to an unfavorable result (Bondemark and r. Kurol, 1992). Concerns with commonly used extraoral devices include socially unacceptable esthetics, the potential for injury, and an

\section{ARTICLE INFORMATION}

*Corresponding Author: ravindrakumar@saveetha.com Received 27th July 2020 Accepted after revision 17th Sep 2020 Print ISSN: 0974-6455 Online ISSN: 2321-4007 CODEN: BBRCBA

Thomson Reuters ISI Web of Science Clarivate Analytics USA and Crossref Indexed Journal

\section{Clarivate Crossef
Analytics}

NAAS Journal Score 2020 (4.31) SJIF: 2020 (7.728)

A Society of Science and Nature Publication,

Bhopal India 2020. All rights reserved.

Online Contents Available at: http//www.bbrc.in/

Doi: http://dx.doi.org/10.21786/bbrc/13.8/110 impractical dependence on patient compliance (Samuels and Brezniak, 2002). The historical success of root-form dental implants to replace missing teeth supported the migration of implantology into orthodontics (Adell et al., 1981; Bra-nemark et al., 1986). The current interest in using implants as osseous anchors for orthodontics may represent a valuable alternative to conventional methods (Odman et al., 1988).

The application of orthodontic forces appears to have a positive effect on peri-implant osseous tissue (Wehrbein and Diedrich, 1993; Akin-Nergiza et al., 1998). Initially, large diameter implants were inserted into the alveolar process, the palate, and the retromolar area. More recently, strategically placed mini-implants, requiring minimally invasive surgery appear to have overcome many of the issues associated with the larger devices. While preliminary data look promising, mini-implants

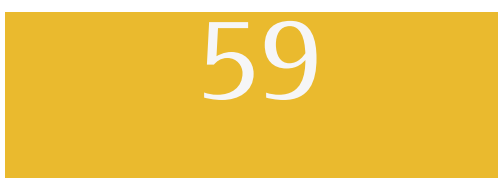


have not equaled the success of root-form devices and concerns regarding design, osseointegration, postinsertion infection, and questions about optimal preload healing time remain subjects for further investigation (Bae et al., 2002; Lobb, 2006)(Costa, Raffainl and Melsen, 1998; Miyawaki et al., 2003)

Survival analysis is the most suitable method to analyze data that have as a principal end point the time until an event occurs. It is a popular method in biomedical research. Survival time can be defined broadly as the time until an event ('The statistical analysis of failure time data. By J.D. Kalbfleisch and R.L. Prentice. John Wiley \&t Sons, Inc., New York, 1980. xi 321 pp. U.S. 31.50, C 40.35. ISBN 0-471-05519-0', 1982; Lee and Wang, 2003). For an orthodontic-implant success-rate study, survival analysis seems to have several advantages. The most important feature of survival analysis is that some subjects in the study have not experienced implant failure at the end of the study or the time of analysis.

We usually cannot determine the exact time of implant failure but can notice that the failure happened only at discrete times,i.e, during patient visits. Survival analysis solves these problems irrespective of the original distribution of data, produces valuable information, including hazard characteristics and survival rates, and identifies risk factors (Lee et al., 2010). The aim of this study was to determine the survival rate of Extra alveolar implants, i.e, Infra-Zygomatic Crest (IZC) and Buccal Shelf (BS) screws, after three months of placement. Also, a questionnaire was distributed to the subjects and their response to extra-alveolar TADs were recorded .

Figure 1: Questionnaire on subject response to Extraalveolar TADS

1. After the placement of the implant, did you have any pain?
(a) Very Mild (b) Mild
(c) Moderate
(d) Severe (e) Very severe

2. Was there any difficulty in opening your mouth during the week after placement of the implant?
(a) Very Mild (b) Mild
(c) Moderate
(d) Severe (e) Very Severe

3. Did you experience any ulcer or swelling in the mouth?
(a) Very Mild (b)Mild
(c) Moderate
(d) Severe (e) Very Severe

4. Did you experience any discomfort during the placement of the implant?
(a)Very Mild
(b) Mild
(c) Moderate
(d) Severe (e) Very Severe

5. Did you experience any discomfort after the placement of the implant? (after 2 weeks)
(a)Very Mild
(b) Mild
(c) Moderate
(d) Severe
(e) Very Severe

\section{MATERIAL AND METHODS}

A total of 32 samples were included for this study. The records of patients who had extra-alveolar TADs placed from July 2019 to January 2020 in the department of orthodontics at Saveetha Dental College and Hospitals were collected. The subjects selected were undergoing fixed orthodontic appliance treatment with MBT bracket prescription. Among the 32 samples of TADs, 7 were Buccal Shelf (BS) implants and 25 were Infra-Zygomatic Crest (IZC) implants. Stability of the TADs were checked with probe and tweezer on the third review. The extraalveolar TADs were used to retract the anterior segment with a controlled tipping force.

A questionnaire of six questions were distributed to the subjects and their data was recorded [Figure.1]. Descriptive Statistics was calculated in terms of frequencies and percentages using SPSS software 23.00. Chi-square association test was also performed to associate the extra-alveolar TADs and the discomforts experienced after its placement .

\section{RESULTS AND DISCUSSION}

Descriptive Statistics was calculated in terms of frequencies and percentages using SPSS software. Chisquare association test was also performed to associate between the extra-alveolar TADs and discomfort experienced by subjects after its placement. Among the total subjects selected $52.94 \%$ were females and 47.06\% were males [Figure.2]. Among these subjects , it was observed that $78.13 \%$ of the TADs placed were Infra-Zygomatic Crest (IZC) implants and 21.88\% wer Buccal shelf (BS) implants [Figure 3]. While assessing the stability of the extra-alveolar TAD, it was found that 93.75\% of the TADs placed were stable and didn't show signs of any mobility [Figure. 4]

Figure 2: Pie Chart representing the percentage of males and females among the sample subjects.

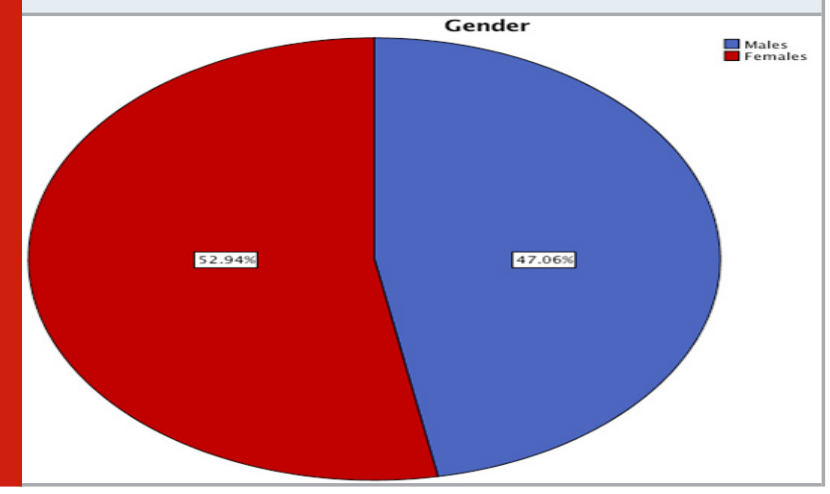

Based on the questionnaire passed to the subjects, it has been inferred that most subjects experience severe form of pain after extra-alveolar TADs placement [Figure.5]. It was also observed that they experienced a mild form of difficulty during mouth opening [Figure.6], and they experienced severe form of ulcer/swelling after extraalveolar TAD placement [Figure.7] . Two weeks after 
placement of the implant, most subjects experienced only mild forms of discomfort [Figure. 8]. Among both IZC and Buccal Shelf implants, IZC was perceived to have only mild discomfort after placement [Figure. 9]. However, this was not found to be statistically significant ( $p$ value - 0.239)

Figure 3: Bar chart representing the type of extra-alveolar TADs used among the subjects. The $\mathrm{X}$-axis represents the type of TADs used and the Y-axis represents the number of extra-alveolar TADs used among the subjects. It was observed that $78.13 \%$ of the TADs placed were InfraZygomatic Crest (IZC) implants.

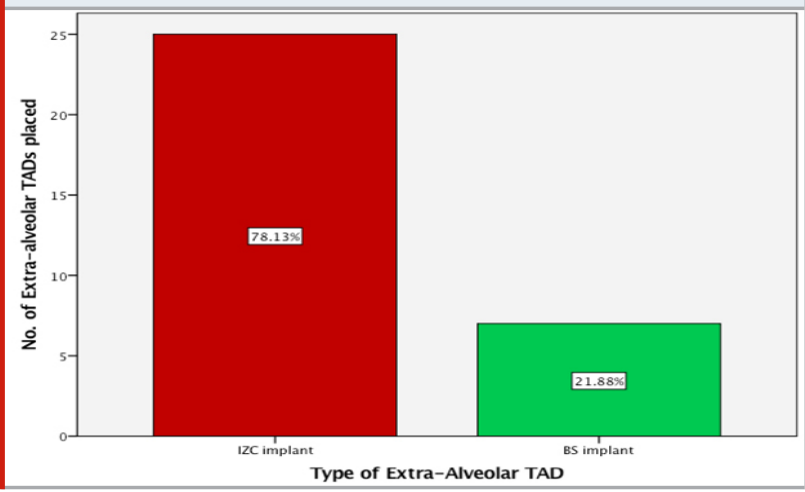

Figure 4: Bar chart representing if there was mobility of extra-alveolar TADs after three months of placement among the subjects. The $\mathrm{X}$-axis represents if mobility was present . The Y-axis represents the total number of extraalveolar TADs placed. It was observed that there was no mobility of TADs placed in about $93.75 \%$ of the samples placed. This was a 3 month survival report.

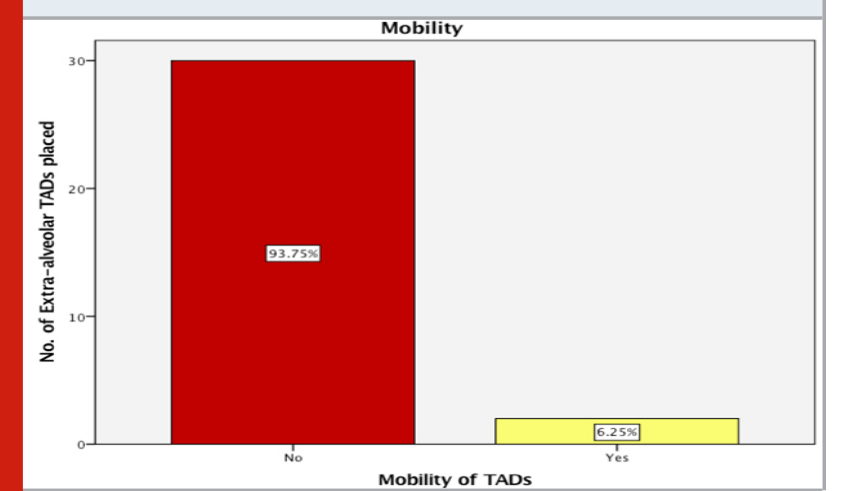

Our extensive research expertise ranged from epidemiological studies to randomised clinical trials that have been published in reputed journals(Felicita, 2017a, 2017b, 2018; Felicita, Thirumurthi and Jain, 2017; Korath, Padmanabhan and Parameswaran, 2017; Krishnan, Pandian and Rajagopal, 2017; Charles et al., 2018; Pandian, Krishnan and Kumar, 2018; Reddy et al., 2018; Chinnasamy et al., 2019). This knowledge was instrumental for us to assess the survival rate of extraalveolar TADs used for orthodontic anchorage.
Figure 5: Pie chart representing the frequency distribution of pain experienced after extra-alveolar TAD placement. Majority of the subjects experienced moderate pain after TAD placement (41.18\%).

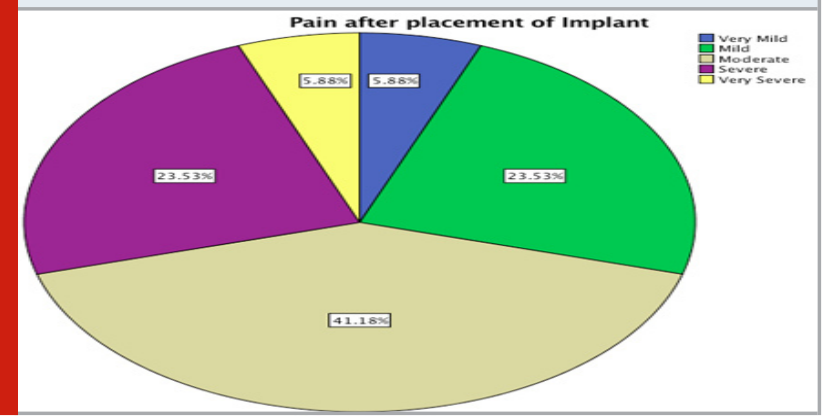

Figure 6: Pie chart representing the frequency distribution of difficulty in mouth opening after extra-alveolar TAD placement. It was observed that most subjects experienced severe difficulty in mouth opening (35.29\%) after placement of extra-alveolar TAD.

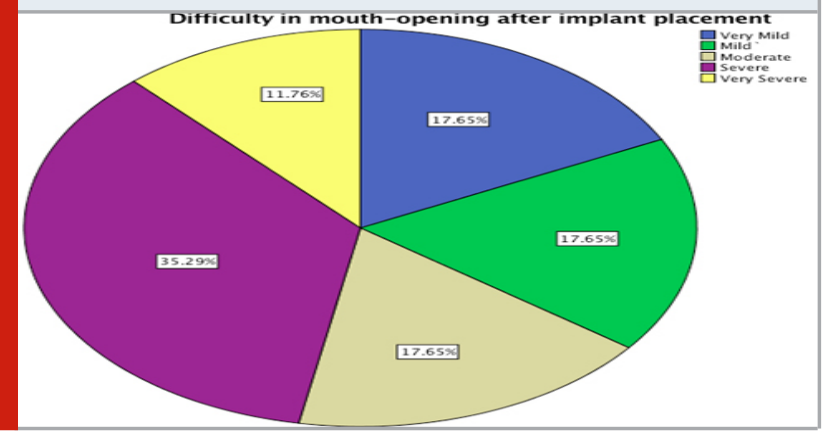

Figure 7: Pie chart representing the frequency distribution of occurrence of ulcer /swelling after the placement of extra-alveolar TADs. It was observed that most people experienced mild to severe forms of ulcers/ swelling after implant placement (35.29\%).

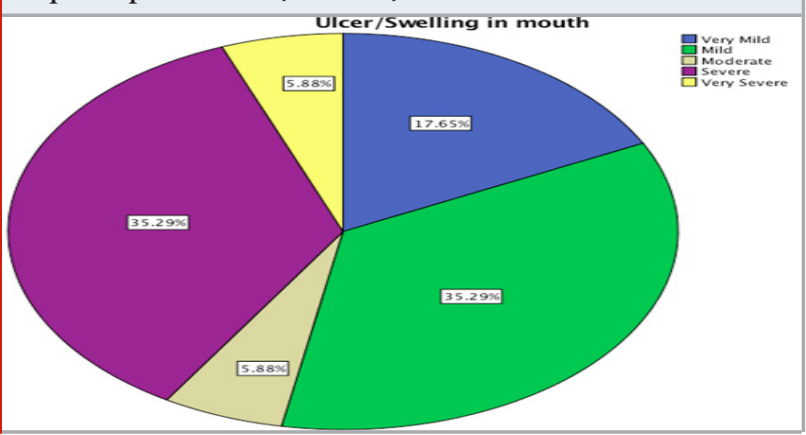

In the present study it has been observed that the 3 month survival rate was acceptable in the majority of the cases. The subjects presented with stable and non-mobile extra-alveolar implants. The overall rate of success was 93.75\%. This is favourable to reports by Park et al (Park, Kwon and Kwon, 2004), and Buchter et al (Büchter et al., 2005), who have reported $80 \%$ or greater success rates. According to previously published systematic reviews and meta-analyses, overall failure rates of mini- 
implants seem to be approximately $13-14 \%$. There was no one specific reason for failure rates of mini-implants. However, it is often followed by mobility which is further accompanied by inflammation(Papageorgiou, Zogakis and Papadopoulos, 2012).

Figure 8: Pie chart representing the frequency of discomfort experienced by the patient 2 weeks after the placement of extra-alveolar TADs. It was observed that majority experienced only mild discomfort after the placement of extra-alveolar TAD $(41.18 \%)$

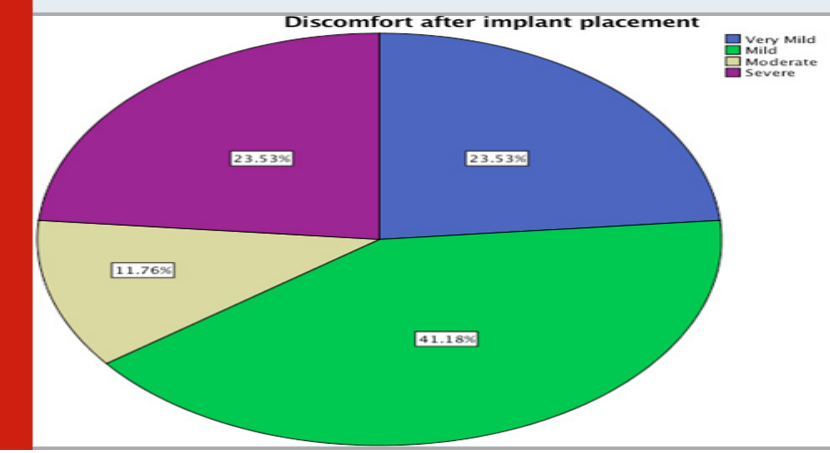

Figure 9: Bar graph representing the association between the type of extra-alveolar TAD and the discomfort faced by patients after placement of the implants. $X$ axis represents the type of implant, $y$ axis represents the number of subjects in whom implants were placed. Chi square association test was done and was found to be non-significant. Chi square value-4.218. df-3, p value0.239 . It was inferred that most subjects with IZC implant experienced only mild discomfort compared to BS implant ; however this is not statistically significant ( $p>0.05)$

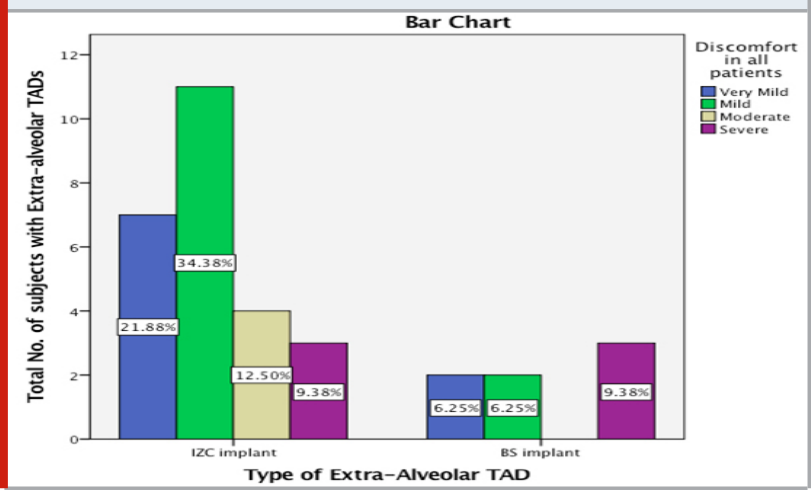

Many studies have investigated the failure rate of TADs relative to a range of variables, such as gender, age, site of insertion, latency of loading, operator experience, and the physical characteristics of the screws. There has been some confusion in defining the failure of TADs in studies when they lose their ability to provide anchorage after they have met their goal, but while treatment continues (Miyawaki et al., 2003; Moon et al., 2008; Bayat and Bauss, 2010; Dalessandri et al., 2014). Most studies also include infection or inflammation as evidence of failure in addition to mobility (Wiechmann, Meyer and Büchter, 2007a; Chen et al., 2008; Viwattanatipa et al., 2009)
Lee et al. , carried out a survival analysis on 260 orthodontic implants (miniscrews) of the same type, and found a failure rate of $8.5 \%$, representing 22 screws (Lee et al., 2010). Janssen et al, attempted to summarize the findings from 50 articles through a systematic review of studies published up to 2006 (Janssen et al., 2008). They were able to conclude that in humans, TADs have a success rate of 70-100\% (Lee et al., 2010). The authors cautioned that randomized clinical trials should be conducted to determine more precisely the influence of the many variables that can contribute to the success or failure of TADs (Wiechmann, Meyer and Büchter, 2007b).

The limitations of this study include a small sample size, retrospective design and sampling technique.

\section{CONCLUSION}

Within the limitations of this study, the following findings were observed:

- A high success rate of $93.75 \%$ and failure rate of $6.25 \%$ was recorded for extra-alveolar TADs.

- Patient discomfort was observed after the placement of the TADs which subsided over a period of 2 weeks.

- Subjects with IZC implants experienced only mild discomfort after placement compared to Buccal shelf implants ; however, this is not statistically significant.

\section{ACKNOWLEDGMENTS}

I would like to record my deep sense of gratitude to my research supervisor Dr Ravindra Kumar Jain, Associate professor, Department of Orthodontics, Saveetha Dental College and Hospitals, Chennai for his guidance and encouragement with my work during all stages. There was an equal contribution from all the authors.

Conflict of Interest: There is no conflict of interest.

\section{REFERENCES}

Adell, R. et al. (1981) 'A 15-year study of osseointegrated implants in the treatment of the edentulous jaw', International Journal of Oral Surgery, pp. 387-416. doi: 10.1016/s0300-9785(81)80077-4.

Akin-Nergiza, N. et al. (1998) 'Reactions of peri-implant tissues to continuous loading of osseointegrated implants', American Journal of Orthodontics and Dentofacial Orthopedics, pp. 292-298. doi: 10.1016/ s0889-5406(98)70211-2.

Bae, S.-M. et al. (2002) 'Clinical application of microimplant anchorage', Journal of clinical orthodontics: JC0, 36(5), pp. 298-302.

Bayat, E. and Bauss, 0. (2010) 'Effect of Smoking on the Failure Rates of Orthodontic Miniscrews', Journal of Orofacial Orthopedics / Fortschritte der Kieferorthopädie, pp. 117-124. doi: 10.1007/s00056-010-9936-8. 
Bondemark, L. and r. Kurol, J. (1992) 'Distalization of maxillary first and second molars simultaneously with repelling magnets', The European Journal of Orthodontics, pp. 264-272. doi: 10.1093/ejo/14.4.264. Bra-nemark, P.-I. et al. (1986) 'Tissue-Integrated Prostheses. Osseointegration in Clinical Dentistry', Plastic and Reconstructive Surgery, pp. 496-497. doi: 10.1097/00006534-198603000-00037.

Büchter, A. et al. (2005) 'Load-related implant reaction of mini-implants used for orthodontic anchorage', Clinical Oral Implants Research, pp. 473-479. doi: 10.1111/j.1600-0501.2005.01149.x.

Charles, A. et al. (2018) 'Evaluation of dermatoglyphic patterns using digital scanner technique in skeletal malocclusion: A descriptive study', Indian journal of dental research: official publication of Indian Society for Dental Research, 29(6), pp. 711-715.

Chen, Y.-J. et al. (2008) 'Stability of miniplates and miniscrews used for orthodontic anchorage: experience with 492 temporary anchorage devices', Clinical oral implants research, 19(11), pp. 1188-1196.

Chinnasamy, A. et al. (2019) 'Chronic nail biting, orthodontic treatment and Enterobacteriaceae in the oral cavity', Journal of clinical and experimental dentistry, 11(12), pp. e1157-e1162.

Costa, A., Raffainl, M. and Melsen, B. (1998) 'Miniscrews as orthodontic anchorage: a preliminary report', The International journal of adult orthodontics and orthognathic surgery, 13(3), pp. 201-209.

Dalessandri, D. et al. (2014) 'Determinants for success rates of temporary anchorage devices in orthodontics: a meta-analysis ( $\mathrm{n}>50$ )', European Journal of Orthodontics, pp. 303-313. doi: 10.1093/ejo/cjt049.

Felicita, A. S. (2017a) 'Orthodontic management of a dilacerated central incisor and partially impacted canine with unilateral extraction - A case report', The Saudi dental journal, 29(4), pp. 185-193.

Felicita, A. S. (2017b) 'Quantification of intrusive/ retraction force and moment generated during enmasse retraction of maxillary anterior teeth using mini-implants: A conceptual approach', Dental press journal of orthodontics, 22(5), pp. 47-55.

Felicita, A. S. (2018) 'Orthodontic extrusion of Ellis Class VIII fracture of maxillary lateral incisor - The sling shot method', The Saudi dental journal, 30(3), pp. 265-269.

Felicita, A. S., Thirumurthi, A. S. and Jain, R. K. (2017) 'Patient's Psychological Response to Twinblock Therapy', World Journal of Dentistry, 8(4), pp. 327-330.

Janssen, K. I. et al. (2008) 'Skeletal anchorage in orthodontics--a review of various systems in animal and human studies', The International journal of oral
Et maxillofacial implants, 23(1), pp. 75-88.

Korath, A. V., Padmanabhan, R. and Parameswaran, A. (2017) 'The Cortical Boundary Line as a Guide for Incisor Re-positioning with Anterior Segmental Osteotomies', Journal of maxillofacial and oral surgery, 16(2), pp. 248-252.

Krishnan, S., Pandian, S. and Rajagopal, R. (2017) 'Sixmonth bracket failure rate with a flowable composite: A split-mouth randomized controlled trial', Dental press journal of orthodontics, 22(2), pp. 69-76.

Lee, E. T. and Wang, J. W. (2003) 'Statistical Methods for Survival Data Analysis', Wiley Series in Probability and Statistics. doi: 10.1002/0471458546.

Lee, S.-J. et al. (2010) 'Survival analysis of orthodontic mini-implants', American journal of orthodontics and dentofacial orthopedics: official publication of the American Association of Orthodontists, its constituent societies, and the American Board of Orthodontics, 137(2), pp. 194-199.

Lobb, W. K. (2006) 'A Mini-Implant for Orthodontic Anchorage in a Deep Overbite Case', Yearbook of Dentistry, pp. 248-251. doi: 10.1016/s00843717(08)70196-x.

Miyawaki, S. et al. (2003) 'Factors associated with the stability of titanium screws placed in the posterior region for orthodontic anchorage', American Journal of Orthodontics and Dentofacial Orthopedics, pp. 373-378. doi: 10.1016/s0889-5406(03)00565-1.

Moon, C.-H. et al. (2008) 'Factors Associated with the Success Rate of Orthodontic Miniscrews Placed in the Upper and Lower Posterior Buccal Region', The Angle Orthodontist, pp. 101-106. doi: 10.2319/121706515.1.

Odman, J. et al. (1988) 'Osseointegrated titanium implants--a new approach in orthodontic treatment', The European Journal of Orthodontics, pp. 98-105. doi: 10.1093/ejo/10.2.98.

Pandian, K. S., Krishnan, S. and Kumar, S. A. (2018) 'Angular photogrammetric analysis of the soft-tissue facial profile of Indian adults', Indian journal of dental research: official publication of Indian Society for Dental Research, 29(2), pp. 137-143.

Papageorgiou, S. N., Zogakis, I. P. and Papadopoulos, M. A. (2012) 'Failure rates and associated risk factors of orthodontic miniscrew implants: a meta-analysis', American journal of orthodontics and dentofacial orthopedics: official publication of the American Association of Orthodontists, its constituent societies, and the American Board of Orthodontics, 142(5), pp. 577-595.e7.

Park, H.-S., Kwon, T.-G. and Kwon, O.-W. (2004) 'Treatment of open bite with microscrew implant anchorage', American Journal of Orthodontics and 
Dentofacial Orthopedics, pp. 627-636. doi: 10.1016/j. ajodo.2003.07.019.

Reddy, A. K. et al. (2018) 'Comparative Evaluation of Antimicrobial Efficacy of Silver, Titanium Dioxide and Zinc Oxide Nanoparticles against Streptococcus mutans', Pesquisa brasileira em odontopediatria e clinica integrada, 18(1), p. e4150.

Samuels, R. H. A. and Brezniak, N. (2002) 'Orthodontic facebows: safety issues and current management', Journal of Orthodontics, pp. 101-108. doi: 10.1093/ ortho/29.2.101.

'The statistical analysis of failure time data. By J.D. Kalbfleisch and R.L. Prentice. John Wiley \& Sons, Inc., New York, 1980. xi 321 pp. U.S. 31.50, C 40.35. ISBN 0-471-05519-0' (1982) Canadian Journal of Statistics, pp. 64-66. doi: 10.2307/3315078.

Viwattanatipa, N. et al. (2009) 'Survival analyses of surgical miniscrews as orthodontic anchorage', American Journal of Orthodontics and Dentofacial Orthopedics, pp. 29-36. doi: 10.1016/j.ajodo.2007.06.018.

Wehrbein, H. and Diedrich, P. (1993) 'Endosseous titanium implants during and after orthodontic load - an experimental study in the dog', Clinical Oral Implants Research, pp. 76-82. doi: 10.1034/j.16000501.1993.040203.x.

Wiechmann, D., Meyer, U. and Büchter, A. (2007a) 'Success rate of mini- and micro-implants used for orthodontic anchorage: a prospective clinical study', Clinical oral implants research, 18(2), pp. 263-267.

Wiechmann, D., Meyer, U. and Büchter, A. (2007b) 'Success rate of mini-and micro-implants used for orthodontic anchorage: a prospective clinical study', Clinical oral implants research. Wiley Online Library, 18(2), pp. 263-267. 